\title{
periferio
}

\section{NARRATIVAS EM PRIMEIRA PESSOA: EXPERIÊNCIAS DOCENTES, GÊNERO E SEXUALIDADES}

\author{
Paulo Melgaço da Silva Junior ${ }^{1}$ \\ Universidade Federal do Rio de Janeiro- UFRJ \\ Marcio Caetano ${ }^{2}$ \\ Universidade Federal do Rio Grande- UFRG
}

\section{Resumo}

Neste texto, seguimos o entendimento de que as identidades são marcadas pela cultura, e reconhecemos a possibilidade de reinvenção do sujeito nos jogos interpelativos das regulações sexuais. Contudo, parece-nos que, independentemente de nossas trajetórias, intuímos as formas de ser, de estar ou de transitar nos marcadores político-sexuais 'mulher' e 'homem', tomando por base - e caminho - os instrumentos que nos educaram. Desse modo, a partir de experiências docentes descritas por meio das contribuições autoetnográficas, neste trabalho buscaremos questionar as práticas pedagógicas de gêneros e de sexualidades, com vista a interrogá-las sobre os discursos que tanto produziram modos de subjetivação quanto nos ensinaram formas heteronormativas complementares e assimétricas de projeção das performatividades sexuais. Como resultado, enfatizamos a importância de problematizar a produção discursiva e social das categorias de gêneros, chamando a atenção para as configurações identitárias elaboradas em diálogo com os instrumentos educativos que nos ensinam formas de ser homem e mulher. Neste processo, percebemos que a "masculinidade" e "feminilidade" têm sido ampliadas e o corpo anatômico é apenas um suporte de invenções estimuladas pela sexualidade. Os novos arranjos proporcionados pelas sexualidades e pelos gêneros improvisam outros arranjos identitários interagindo com os movimentos curriculares e produzindo tensões cotidianas na escola.

Palavras-chave: heteronormatividade; currículo; escola

\footnotetext{
1 Professor da Educação Básica nas redes de Ensino do Estado do Rio de Janeiro e Prefeitura Municipal de Duque de Caxias e pós-doutorando em Educação pela UFRJ. pmelgaco@uol.com.br

2 Docente na Universidade Federal do Rio Grande- FURG e Líder do Nós do Sul - Laboratório de Estudos e Pesquisas Sobre Identidades, Currículos e Culturas. mrvcaetano@gmail.com
} 


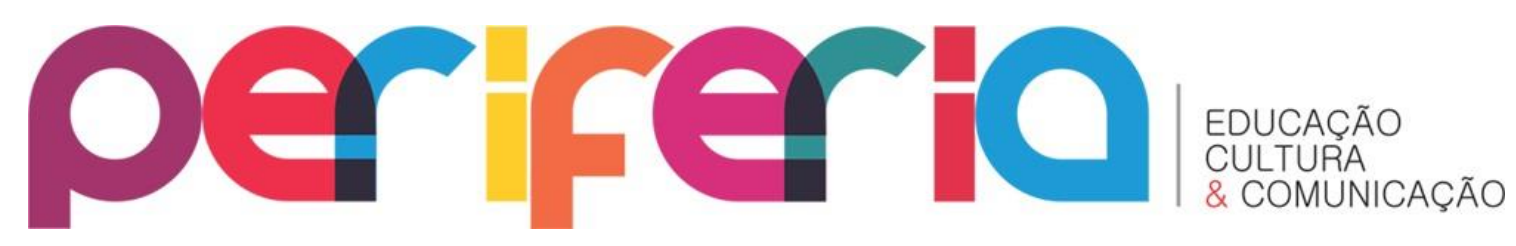

\section{FIRST-PERSON NARRATIVES: TEACHING EXPERIENCES, GENDER AND SEXUALITIES}

\section{Abstract}

The present text is based on the idea that the so-called identities are marked by culture, and on the acknowledgement that it is possible to reinvent the notion of 'subject' in the interpellation games for sexual regulations. However, despite our trajectories we sense the forms of being or of rambling through the notions of 'woman' and 'man' as political and sexual markers. Such sense derives from the instruments that have based and paved the way towards our education and therefore have molded us. Thus, it is our goal to question the pedagogical practices around gender and sexualities. In order to do so, we generated data from teachers' experiences that were, in their turn, described and analyzed on the autoethnographic perspective and its contributions. The intention was to question such experiences about the discourses that have both produced forms of subjectivity, and taught us asymmetric and complementary heteronormative forms of sexual performativity projections. The results emphasizes the importance in questioning the social and discursive production of the gender categories focusing on the identity configurations elaborated in a dialog with the educative instruments which teach us ways of being a man or a woman. We understand that "masculinity" and "femininity" have grown wider and the anatomic body is just a support of inventions that have been stimulated by the sexuality. The new arrangements produced by the sexualities and by the genders improvise other identity arrangements interacting with the educational program transformations and producing usual tensions at the school.

Keywords: heteronormativity; curriculum; school 


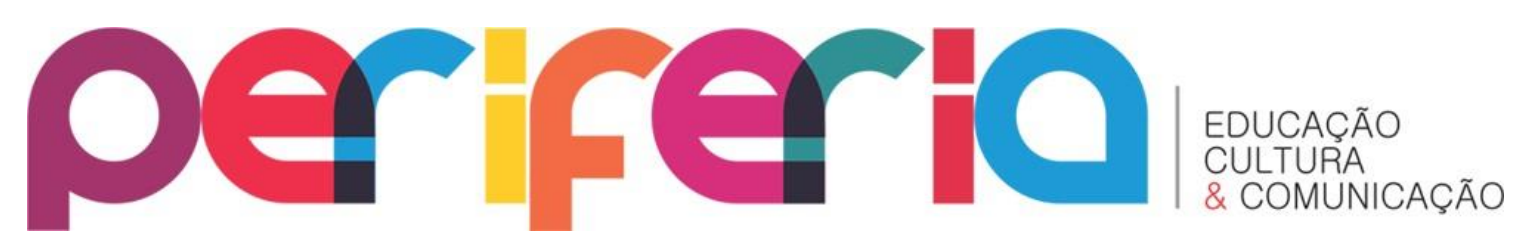

\section{ASPECTOS INTRODUTÓRIOS}

Apresentam-se, neste artigo, a experiência autoetnográfica docente estabelecida na perspectiva interativa com estudantes. 0 intercâmbio em tela ocorreu entre um dos autores e os demais sujeitos que circulavam nas escolas públicas em que atuava como docente. Quanto aos estudantes, eles eram de duas escolas públicas localizadas em Guapimirim e São Gonçalo, cidades do estado do Rio de Janeiro.

Nas escolas, no período de um ano letivo, procedeu-se à produção de dados a partir da experiência autoetnografia. É importante ressaltar que, por razões de cunho ético, os nomes e as características de identificação das escolas foram alterados. Desse modo, asseguramos a impossibilidade de identificação dos sujeitos e das instituições envolvidos nesta pesquisa, sem causar, entretanto, qualquer prejuízo ao processo de análise dos dados e à apresentação dos resultados.

A autoetnografia é uma ferramenta importante para produzir sentido sobre a experiência. Enquanto preponderantemente derivada dos paradigmas interpretativo, ecológico e interacionista-simbólico, a autoetnografia pode conferir à pesquisa um aparato teórico que vai além do 'tradicional' mecanismo investigativo, isto é, a adoção de uma metodologia científica derivada da pesquisa qualitativa.

O método autoetnográfico propõe uma pesquisa social pautada numa prática menos engessada segundo a qual o/a pesquisador/a, em princípio, não precisa suprimir sua subjetividade, como preconizada hegemonicamente pelo discurso científico na maior parte dos séculos XIX e XX. Desse modo, a autoetnografia se propõe a refletir o campo e suas produções em suas dimensões emocional, espiritual, intelectual, corporal e moral. Centrada na autorreflexão do sujeito investigado/investigador, a autoetnografia pode possibilitar o re-conhecimento das dimensões subjetivas envolvidas no processo investigativo. 


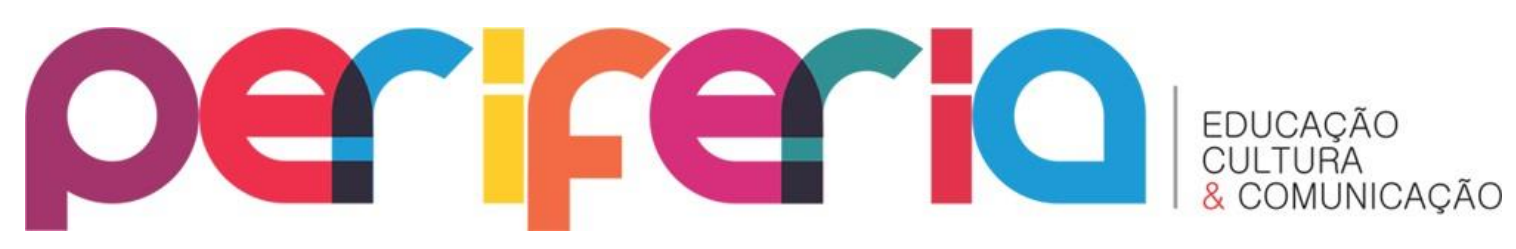

[...] Existem cinco chaves para a construção da autoetnografia: (1) visibilidade para o si: é o eu do pesquisador se tornando visível no processo, este eu não é separado do ambiente, ele só existe na relação com o outro, é, portanto, o eu conectado com o seu entorno; (2) forte reflexividade: representa a consciência de si e a reciprocidade entre o pesquisador e os outros membros do grupo, o que conduz a uma introspecção guiada pelo desejo de entender ambos; (3) engajamento: em contraste com a pesquisa positivista que assume a necessidade de separação e objetividade, a autoetnografia clama pelo engajamento pessoal como meio para entender e comunicar uma visão crítica da realidade, de forma que engajamento, negociação e hibridez emergem como temas comuns de uma variedade de textos autoetnográficos; (4) vulnerabilidade: a autoetnografia é mais bem-sucedida quando é evocativa, emocionalmente tocante e quando os leitores são tocados pelas histórias que estão lendo, certamente isto traz algumas vulnerabilidades ao explorar a fraqueza, força, e ambivalências do pesquisador, evocando a abertura de seu coração e mente; (5) rejeição de conclusões: a autoetnografia resiste à finalidade e fechamento das concepções de si e da sociedade, pois é concebida como algo relacional, processual e mutável (MOTTA; BARROS, 2015, $\mathrm{s} / \mathrm{d})$.

Para o/a pesquisador/pesquisadora, o conhecimento adquirido pela autoetnografia ultrapassa a gênese da construção acadêmico-intelectual, qual seja, a de buscar a neutralidade, a cientificidade objetiva e a percepção particular sobre o outro. Na pesquisa interativa colaborativa, a elaboração reflexiva sobre o existir se faz necessária a todos os sujeitos envolvidos na investigação. Enquanto atribuidora de sentido às atividades cotidianas, a autoetnografia impõe aos sujeitos da investigação uma posição privilegiada de intérpretes das situações vividas, ainda que para isso necessite obrigatoriamente de elementos disponíveis em seus espaços de interação.

A autoetnografia propicia aos/às participantes um distanciamento da ideia de realidade diária - que, muitas das vezes, lhes é invisibilizada pelo caráter rotineiro das ações cotidianas - exatamente porque os/as obrigam ao exercício de atribuição de sentido ao vivido. Dão-se margens, portanto, à reflexividade e à relativização do sentido imediato atribuído a uma ação. Numa perspectiva freireana, isso significa “colocar em destacado" as questões 


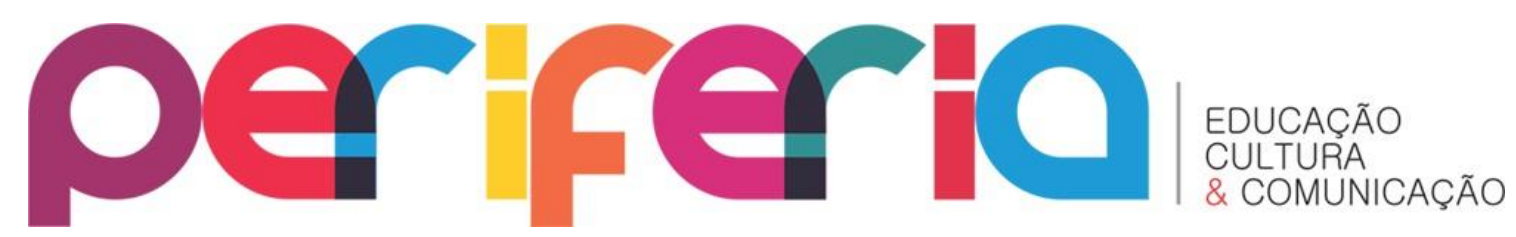

diárias, para refletir sobre elas (FREIRE, 1996). Neste momento, é criado um novo sentido, mais elaborado e problematizado, dando uma dimensão crítica ao vivido e possibilitando sua reelaboração significativa.

Nessa autoetnografia da prática docente, os fazeres diários foram revisitados por meio das experiências de um professor-pesquisador-autor. As narrativas que se seguem apresentam ao/à leitor/leitora um 'cenário familiar', mas que tornaremos 'estranho' para que novos olhares e novas leituras sejam possíveis a cada um/uma. Assim, a narrativa autoetnográfica da experiência escolar é apresentada na primeira pessoa do singular, enquanto a narrativa que faz referência às interpretações colaborativas entre os autores é apresentada na primeira pessoa do plural.

\section{COMO DISSE MARCELA LAGARDE": "NUESTRAS VIDAS SON VERDADEIRAS ESPISTEMOLOGÍAS"}

As histórias que marcam nossas trajetórias profissionais, e que ainda povoam a forma como nos constituímos professores/professoras, passaram a ser vistas sob outros prismas a partir do momento em que as problematizamos para a escrita deste artigo. Interrogar nossas narrativas, em um encontro polifônico inspirado em Bakhtin (2002), não foi uma escolha gratuita. As narrativas constituíram-se como espaços férteis à heterogeneidade enunciativa. Isso se deve ao fato de que nelas os locutores retomaram, implícita ou explicitamente, discursos outros, fazendo ouvir vozes e/ou os diálogos entre as personagens das experiências vividas.

Nesse caminho, estamos tecendo e cruzando os fios de experiências que ficaram momentaneamente 'apagadas' no e com o tempo, mas que foram

\footnotetext{
${ }^{3}$ Deputada mexicana, ela presidiu a Comissão Especial da Câmara de Deputados que deu seguimento às investigações sobre o feminicídio. A investigação subsidiou seus argumentos na aprovação da Ley General de Acceso de las Mujeres a una Vida Libre de Violencia (MEXICO, 2007). Mais detalhes da lei consultar: http://www.gob.mx/cms/uploads/attachment/file/209278/Ley_General_de_Acceso_de_las_ Mujeres_a_una_Vida_Libre_de_Violencia.pdf, acessado em 20/06/2017. A frase que subtitula a seção foi dita a um dos autores em conversa informal em 2010 quando de seu estágio doutoral na UNAM
} 


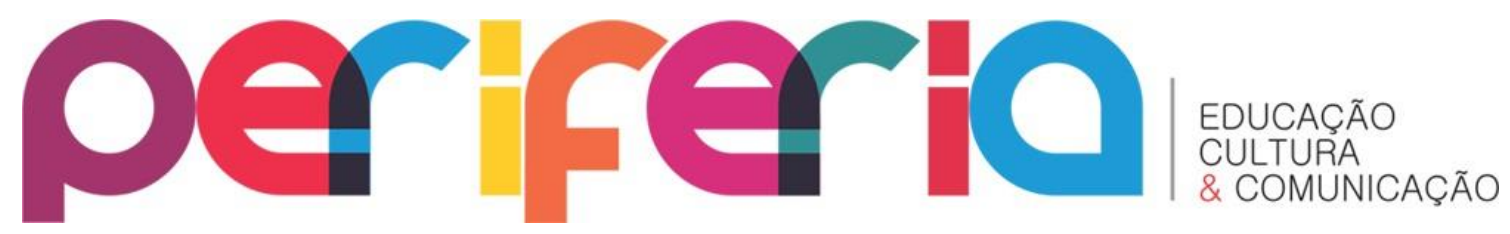

reencontradas a partir dos diálogos para a escrita deste artigo. 0 que pretendemos não é somente trazer informações sobre práticas docentes, mas convidar à reflexão aqueles/aquelas que delas se sintam personagens. A vida cotidiana oferece uma multiplicidade de momentos, de lugares, de espaços, de situações e de relações nas quais se originam atos formativos de aprendizagens. Ela constitui lócus privilegiado da experiência, do saber e do conhecimento (LARROSA BONDÍA, 2002).

Entendemos que na interseção entre gênero, sexualidade e práticas pedagógicas, aprofunda-se a compreensão de processos micropolíticos que se entrelaçam nas relações curriculares, fortemente marcadas pela heteronormatividade ${ }^{4}$ e pelo androcentrismo ${ }^{5}$. Questões que ficam encobertas, entre outros motivos, pela 'naturalidade' que são atribuídas às identidades, aos fazeres e aos desejos sexuais e, sobretudo, aos lugares ocupados por homens e por mulheres nas instâncias e nas dinâmicas da vida. Diante do fato, neste texto, preocupamo-nos em problematizar, por meio das experiências docentes de um dos autores, as práticas pedagógicas heteronormativas que produziram modos de subjetivação, articulando e hierarquizando saberes, posicionando os sujeitos e regulando as projeções, desejos e, especialmente, comportamentos nas escolas.

\footnotetext{
4 Ela constitui-se como sistema político-subjetivo que mantém a lógica dicotômica e complementar entre homens e mulheres. O sistema heteronormativo, para se manter na ordem das coisas, necessita retroalimentar-se da lógica sexual binária. Daí a necessidade de ideologicamente controlar as tecnologias pedagógicas da escola e mais amplamente da cultura. Nesses pressupostos, articulam-se as identidades e as práticas curriculares (CAETANO; GOULART; SILVA, 2016).

5 Ele não se limita ao simples jogo entre uma 'supremacia' masculina e uma 'submissão' feminina. $\mathrm{O}$ androcentrismo caracteriza-se pela cadeia de responsabilidade que é cobrada aos homens e os levam a naturalizar o governo das instâncias da vida. Ele funciona como uma prisão que, aliada à heteronormatividade, é o ponto de partida da homofobia, da lesbofobia e da transfobia. Caetano (2016) argumenta que existe uma aproximação que nos obriga a ver a misoginia, o androcentrismo e a heteronormatividade como conceitos que se entrecruzam na manutenção do patriarcado. Para o autor, a heteronormatividade se conecta diretamente com o androcentrismo e com a misoginia. Primeiro, porque sustenta a ideia do governo homem/masculino sobre a mulher/feminino, inclusive sobre o que é produzido pelo e com o corpo da mulher. Segundo, porque, ao exigir as tarefas de governo do homem e de governada da mulher, thes obrigam a relações intrínsecas e reprodutivas do sistema em uma lógica binária.
} 


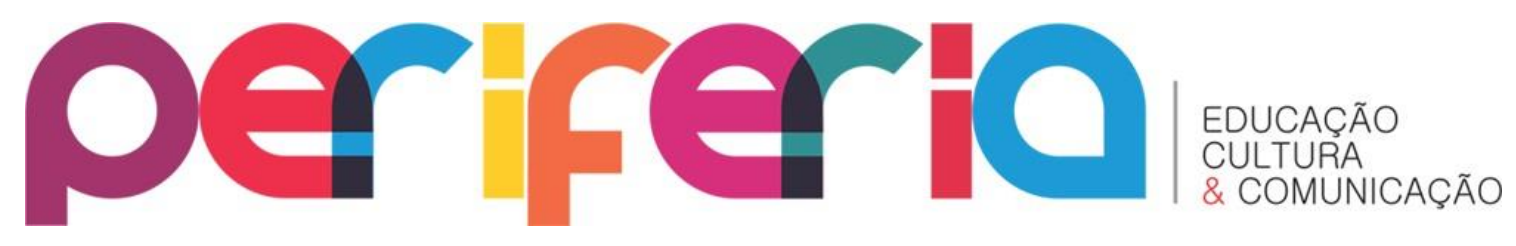

Como parte das instituições que interagem na e integram a sociedade, a escola tem em seu interior sujeitos que trazem de suas relações mais amplas as aprendizagens que se configurarão nos currículos. Isso significa assumir que, independentemente de prescrições, os currículos caracterizamse como espaços privilegiados de encontros de leituras de mundo. Mesmo reconhecendo a legitimidade e a força de conteúdos curriculares prescritivos, a potencialidade e os conhecimentos gerados por meio das relações constituídas nos espaços escolares serão frutos de tensões culturais de seus diversos sujeitos. Assim, os currículos, ainda que carentes de reflexão, não são ações sem resultados na vida. Eles são configurados por sistemas de interesses elaborados tanto pelos sujeitos que estão nas escolas, quanto por aqueles que, na gestão, orientam/determinam o que deve ser ensinado na escola.

Com Caetano (2016), sabemos que os currículos também fazem parte dessas práticas educativas que ensinam a heteronormatividade e o androcentrismo. Muitos sujeitos consideram que os significados em torno dos sexos anatômicos (pênis e vagina), gêneros e sexualidades são dimensões que todos nós possuímos 'naturalmente'. Assumindo esse quadro como a verdade, tornam-se desprovidas de sentido quaisquer argumentações sobre as dimensões social, cultural, política, geográfica e histórica dos princípios construídos dos sexos anatômicos, das sexualidades e das performatividades de gênero em seus aspectos mais amplos.

Considerando o já dito, esse artigo imerge em práticas docentes em escolas públicas de São Gonçalo e de Guapimirim (ambas no estado do Rio de Janeiro). Foram por meio delas que as primeiras percepções de práticas cotidianas e pedagógicas de construção das masculinidades foram sentidas.

Em São Gonçalo (RJ), conheci, em 2012, Jonathan. Naquela época, esse rapaz tinha, aproximadamente, 14 anos de idade e já havia repetido a $6^{\text {a }}$ série duas vezes. Diferentemente de outros/outras estudantes, Jonathan articulava as palavras escritas e as oralizadas e demonstrava conhecimentos básicos dos conteúdos exigidos dos/das estudantes daquela série. Ao iniciar as 


\section{periferio}

investigações sobre a situação escolar de Jonathan, descobri que as duas retenções foram causadas pelas faltas.

Durante as investigações sobre a evasão escolar de Jonathan, em certa manhã de uma segunda-feira, chegando à escola, observei uma professora de matemática discutindo acaloradamente com estudantes na quadra poliesportiva. Não se tratava simplesmente de uma advertência docente aos/às estudantes indisciplinados/indisciplinadas. Naqueles minutos de embate, era possível perceber que o corpo da professora se movimentava com muita raiva. Ainda que a leitura do fato possa aparecer exagerada, seu comportamento seguramente era limitado pelas regras exigidas aos/às docentes nos espaços escolares ${ }^{6}$. Em outros ambientes, seriam verbalizadas palavras mais agressivas àqueles/àquelas alunos/alunas.

A escola em questão possuía alguns elementos arquitetônicos importantes à análise e por isso será citada. As paredes das salas de aula faziam duplo papel: definiam os espaços da escola e os separavam da rua. 0 portão principal da escola ficava em uma rua movimentada da cidade. 0 espaço físico da escola levava os/as alunos/alunas a se concentrarem, antes das aulas, na quadra poliesportiva, única tecnologia de lazer, onde existiam dois banheiros individuais (um masculino e um feminino) e possibilitava a qualquer pessoa o contato imediato com a estrutura administrativa (a secretaria) e o Serviço de Orientação Educacional (SOE).

O espaço limitado e a arquitetura dessa escola reproduzem, em muito, a forma desigual com que homens e mulheres devem ocupar os espaços comuns, convencionalmente chamados de públicos. No intervalo, os/as alunos/alunas eram obrigados/obrigadas a recrearem na quadra poliesportiva que, dada a sua precariedade, somente ocorriam partidas de futebol. Como já sabemos, essa prática esportiva ainda é majoritariamente praticada por homens e seu exercício por mulheres é atravessado por muitos preconceitos.

\footnotetext{
${ }^{6}$ Mary Rangel, em seu trabalho Representações e reflexões sobre o 'bom professor (2001), nos apresenta um minucioso quadro dos comportamentos e das expectativas de um/uma bom/boa professor/professora.
} 


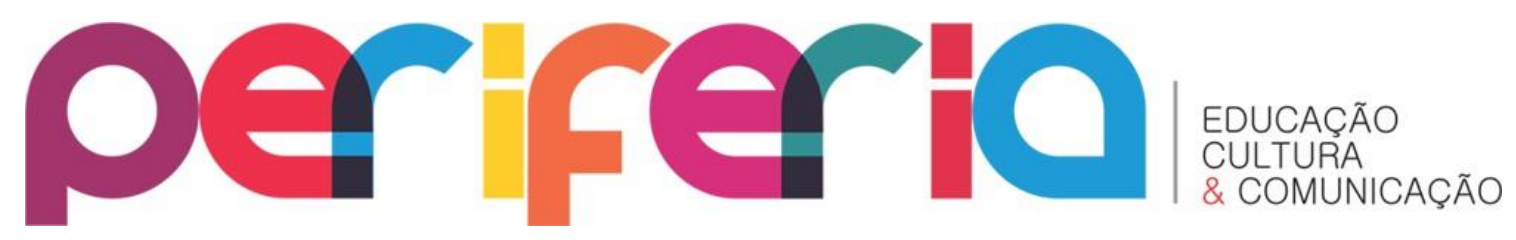

Nesse sentido, a quadra esportiva era ocupada pelos meninos, o que obrigava as alunas a se manterem nos contornos da quadra. Outro fator que as limitava espacialmente era o uso do banheiro: graças às formas diferenciadas de uso dos reservados e estarem em maior número, elas eram levadas a se dirigirem aos banheiros antes dos meninos. Como existia somente um reservado para elas que, quantitativamente, eram em maior número, seu tempo de lazer era, consequentemente, diminuído. Os meninos eram duplamente beneficiados, eram em menor número e o quantitativo de espaços às suas necessidades fisiológicas eram maiores (somando-se os vasos e os mictórios) que no banheiro feminino.

O quadro narrado acima reforça a ideia de que as práticas mais sutis e insignificantes educam os sujeitos para as diferenças sexuais e, no geral, naturalizam a supremacia e as necessidades dos homens. Alguém poderia perguntar: "Por que as estudantes não reclamavam?" Não sei ao certo se havia reclamação, o que posso afirmar é que, durante os dois anos em que estive nessa escola, o cenário repetiu-se. Entretanto, a forma desigual com que somos educados/educadas nos leva a naturalizar os modos como os homens e as mulheres devem ocupar e usar o espaço público. Essas formas educativas são, por vezes, insignificantes, mas, em vários momentos, são carregadas de afeto e proteção.

Mabel Burin no Diplomado Internacional El feminismo en América Latina: aportaciones teóricas y vindicaciones ${ }^{7}$, ao debater a temática 'Empoderamiento, trabajo y subjetividad de las mujeres', apresentou uma charge que, mesmo sendo uma representação caricaturada das formas entendidas como insignificantes que educam para a natureza das desigualdades entre homens e mulheres, é um desenho muito próximo do que é possível observar cotidianamente.

\footnotetext{
7 O curso de seis meses foi oferecido, em 2010, pelo Centro de Investigações Interdisciplinares em Ciências e Humanidades da Universidade Nacional Autônoma de México - DF - México.
} 


\section{periferio}

Imagem 01

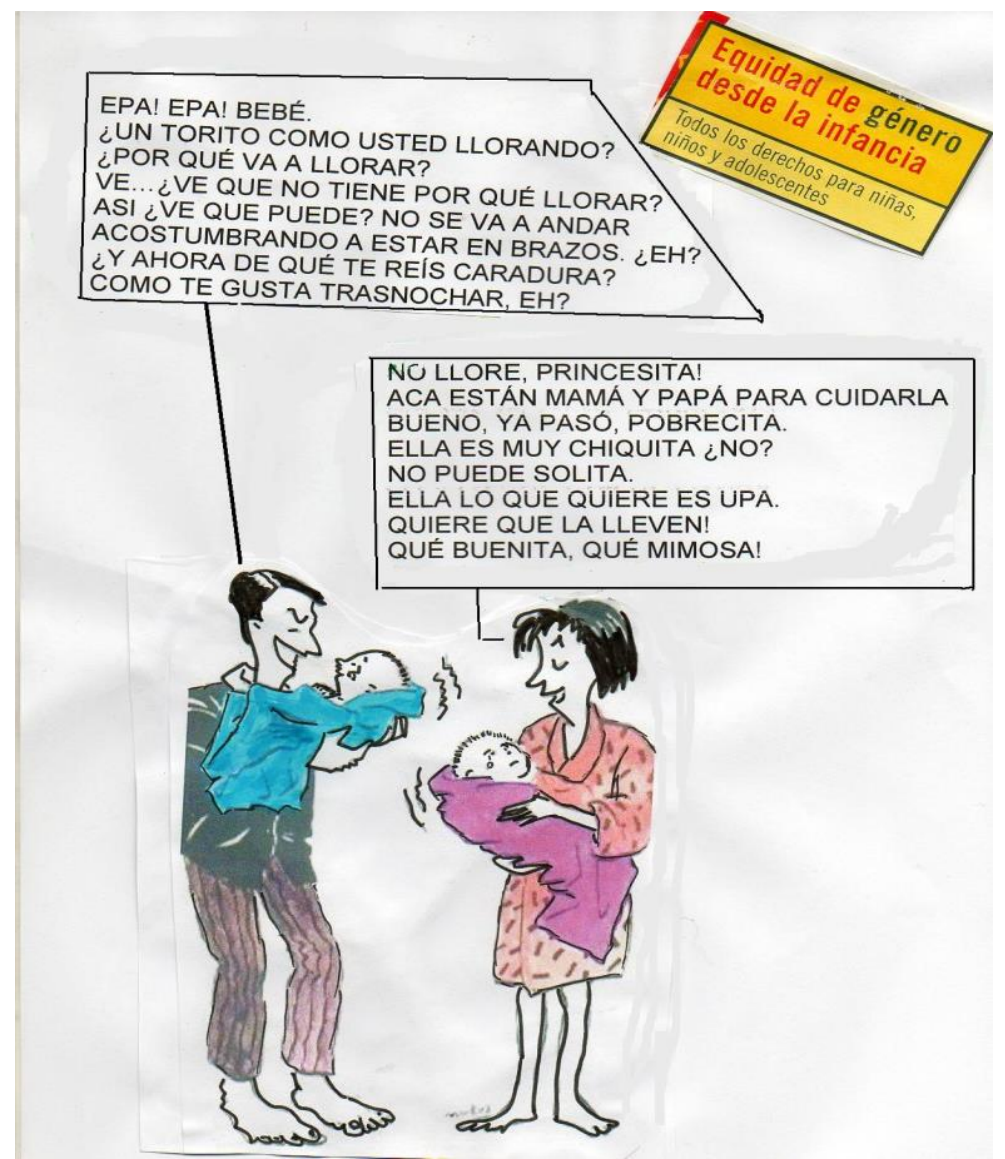

Fonte: Arquivo pessoal de Mabel Burin apresentado no curso Empoderamiento, trabajo y subjetividad de las mujeres no Diplomado Internacional El feminismo en América Latina: aportaciones teóricas y vindicaciones. Universidade Nacional Autônoma de México, 2010..

Com efeito, não consideramos que as características, as linguagens e os acessórios culturais que educam e ganham sentidos diferentes para mulheres e homens sejam estáticos, entretanto, desde muito pequenos/pequenas, vamos sendo apresentados/apresentadas a comportamentos e a símbolos que vão, paulatinamente, construindo nossos contornos sexuais. Esses serão por nós reivindicados e usados para nos separar entre as categorias 'homens' e 'mulheres'. Contudo, tais práticas não somente nos separam, como também nos dizem como devemos nos posicionar frente à vida.

Os discursos da caricatura estão marcados pelo afeto, entretanto, o paterno volta-se à fortaleza e à (auto)defesa; ao passo que o materno 


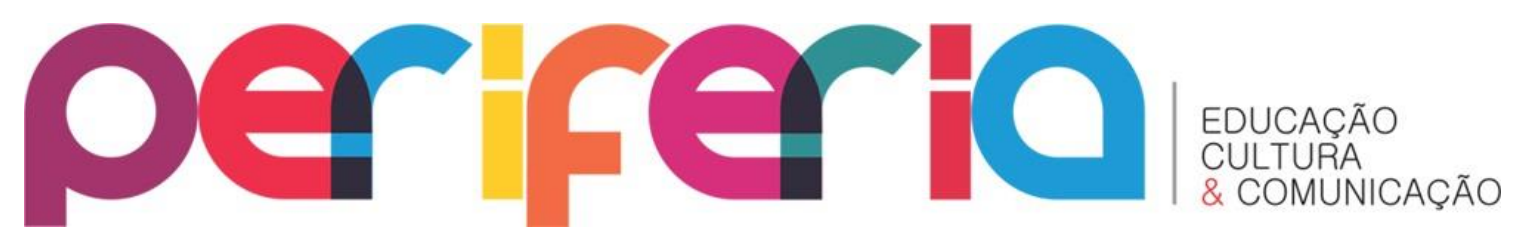

enfatiza, no diminutivo, a debilidade e a necessidade de proteção que a "pobrecita" necessita. Mesmo respeitando a historicidade do texto de Beauvoir (2005), e reconhecendo as implicações resultantes, pensamos que sua afirmação abre caminho à reflexão: “la 'mujer, mujer' es un producto artificial que fabrica la civilización con antes se fabricavan castrados" ( $\mathrm{p}$. 521). Cotidianamente, nos espaços sociais são reforçados o androcentrismo, por meio de práticas educativas de grandes ou de sutis impactos. Essas práticas educativas são resultantes das relações sociais e culturais e, por isso, suas consciências para mulheres e homens estão naturalizadas.

Retomemos o episódio envolvendo a professora de matemática e os alunos e alunas na quadra esportiva. 0 ocorrido movimentou a direção e a orientação educacional: todas, naquele momento, haviam parado seus afazeres para assistir à professora advertir enfaticamente os/as alunos/as. Somente alguns dias depois, porém, soube-se a razão do episódio. Foi uma estudante quem relatou o acontecido. Segundo ela, Jonathan era sobrinho da professora de matemática e ela o defendia dos deboches dos demais colegas no jogo de vôlei na aula de Educação Física. Ainda de acordo com a mesma estudante, o deboche ocorria devido à forma como Jonathan arremessava a bola. Seu toque não reunia a força necessária para atravessar a rede de vôlei, e os demais meninos exigiam dele um 'toque de homem'. Essa situação ilustra a afirmativa de Connell (1995): as brincadeiras consideradas 'masculinas' cruzam uma tênue linha entre a violência e a exibição de força física. Desse modo, o gosto pelos esportes e a apresentação da força tornam-se características inerentes e significadas na cultura ao corpo do homem, tornando-se, assim, inerentes a ele.

Jonathan, segundo a estudante que relatou o episódio, era constantemente assediado pelos demais colegas naquela escola, porque seus comportamentos e suas atitudes não correspondiam às expectativas de um adolescente do sexo masculino, de modo que, naquele espaço, suas relações eram marcadas pelas agressões. 


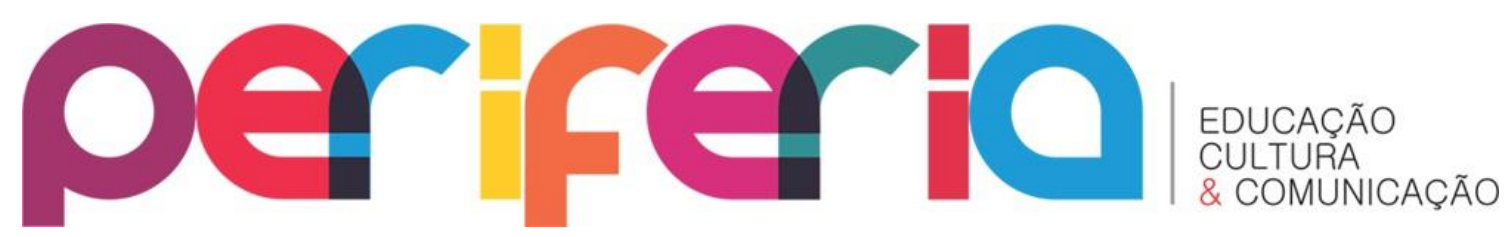

Quando partimos a refletir sobre as experiências de Jonathan, verificamos que elas não representaram a inauguração de nossos contatos com as produções discursivas sobre as masculinidades. No campo cotidiano, elas já faziam parte de nossas vidas e foram inseridas pelas relações sociais vividas, sobretudo, por meio daquelas vivenciadas nas escolas e nas famílias. Nesses espaços, ser homem significa apresentar comportamentos opostos aos esperados das mulheres, e assim fomos educados. A identidade masculina era relacional e, nesse contexto, a relação era estabelecida exclusivamente com as mulheres: eram elas ‘o ponto oposto' que deveria nos orientar.

No tempo histórico, social e cultural de nossas adolescências e juventudes na Baixada Fluminense ou no subúrbio de Belo Horizonte, as mulheres nos serviam de referências para desenhar nossas projeções e nossas expectativas sobre o que era necessário para sustentar a identidade de 'homem'. Mesmo que as fronteiras entre o 'ser homem' e o 'ser mulher' fossem constantemente borradas em nossos comportamentos, aquilo que era entendido como 'a mulher' era o ponto oposto que nos permitia afirmar: "Somos homens!" Para ser homem, é preciso, reiteradamente, afirmar-se como homem (BADINTER, 1993), o que sugere que o percurso e a performance para realizar as regras da masculinidade precisam ser construídos, conquistados e interpretados.

Com base na experiência vivida por Jonathan, cremos que seja importante apontar alguns diagnósticos realizados pela equipe diretiva da escola sobre esse rapaz. Das questões surgidas na escola de Jonathan, duas chamaram-nos à atenção. Ele foi 'diagnosticado' como um aluno 'cheio de problemas com sua sexualidade' e a solução dividiu-se em duas alternativas: (1) encaminhar Jonathan ao serviço psicológico da Prefeitura e (2) juntamente ao encaminhamento, orientá-lo a buscar uma igreja evangélica.

As narrativas das professoras e da diretora eram quase sempre conduzidas por palavras-chave, tipo: 'futuro', ‘doença' e 'prevenção'. Naquele momento, Jonathan apresentava características entendidas como pertencentes aos 'homossexuais'. Nenhuma professora, ou mesmo a direção, 


\section{periferio}

afirmou que Jonathan era homossexual ou mantinha práticas homossexuais, mas deixaram entrever que as configurações do rapaz, naquele presente, representavam um futuro que contrariaria a heterossexualidade e a supremacia masculina.

A preocupação com Jonathan limitava-se ao seu futuro. Graças a sua faixa etária, ele era visto como um corpo sem sexualidade, sem desejo e sem condições de refletir sobre suas ações. Encaminhá-lo ao serviço de psicologia era para reconduzi-lo a um comportamento esperado de um homem, afastando, portanto, de seu corpo masculino, as marcas e os comportamentos entendidos como homossexuais ou seria uma estratégia pedagógica de buscar as respostas à violência vivida por Jonathan em especialistas externas à escola? As razões da equipe para conduzi-lo ao serviço psicológico não foram sabidas; entretanto, são públicas as razões que embasaram a orientação da equipe sobre a busca de ajuda numa igreja evangélica. As instituições religiosas judaico-cristãs hegemonicamente defendem modelos andocêntricos e heteronormativos de projeção de gênero.

O apelo pedagógico ao/à especialista - tanto em psicologia quanto em religião - nos faz lembrar Foucault (1988). Segundo o autor, os estatutos médico-psíquicos não são suficientemente fortes, caso queiram fazer funcionar seus saberes massivamente. Nesse caso, os conhecimentos jurídicos - e suas sequelas nas políticas públicas - e o apoio religioso são parceiros fundamentais nesta corrida pela normatização de comportamentos, e fecham um ciclo de governo eficiente sobre a vida. Esse mecanismo assume um caráter central quando pensamos o governo sobre as sexualidades e a performatividade de gênero marginal.

Neste sentido, os discursos sobre as sexualidades $e$ as performatividades de gênero que nos educam caminham entre uma lei social normatizadora e uma lei natural normalizada. Essa última nos atravessa de tal maneira que integra nossa existência e se aloja em nosso inconsciente. Nesse caso, trata-se de um inconsciente que se constitui com e na cultura, com a 


\section{periferio}

'naturalidade' das configurações sociais e que nada tem a ver com um discurso psicanalítico.

O episódio descrito na quadra, envolvendo estudantes, a professora de matemática e Jonathan, nos dá pistas de como seria entendido o comportamento ideal masculino. A desenvoltura corporal e as expressões afetivas de Jonathan não eram vistas naquele espaço como as de um homem. Aqui a identidade 'homem' limita-se às fronteiras da heterossexualidade e, portanto, a todo o governo que ele representa no corpo do homem e na sua relação com a mulher. Desse modo, a compreensão acerca do comportamento de Jonathan parecia indicar que, no futuro, ele não seria 'homem' e nele se configuraria um terceiro sexo: o não homem e o não mulher.

0 debate até aqui me recorda outra experiência vivida na rede pública de Guapimirim. Numa sala de aula em que alunos/as alunas compartilhavam mesas, chamou à atenção quatros alunas que insistiam em sorrir no exato momento em que explicava o conteúdo. Eram risos baixos, mas contínuos. Depois de uns 10 minutos desse som desestabilizador - que questionava e me dizia, intuitivamente, que algo ocorria e que eu não tinha o controle - resolvi acelerar a aula expositiva e distribuir tarefas sobre o conteúdo exposto. Eu precisava sair daquele centro de olhares. Algo me dizia que o sorriso era motivado por alguma coisa que estava fazendo. Pois bem, uma vez redimensionado o planejamento de aula, eu consegui sair do centro dos olhares e me dirigi à mesa, localizada ao lado direito do quadro, que é oposto à porta de ferro vazado. Essa localização me permitia ver as atividades desenvolvidas na sala de aula e também no corredor, onde estavam os bebedouros e os banheiros.

Finalmente, eu estava na mesma posição corporal das quatro alunas risonhas e seus corpos permaneciam emitindo informações de que eu poderia estar fazendo algo de errado. Entretanto, a minha posição corporal permitia perceber a direção dos olhares das alunas no meu corpo. Estranhamente, os olhos das meninas estavam voltados para os meus pés. Acabava de descobrir que a risada era motivada pelas minhas sandálias, tipo franciscanas. Diante do 


\section{periferio}

enigma que acabara de decifrar, eu caminhei até as risonhas alunas, thes perguntei se minhas sandálias as incomodavam e se elas se sentiam desrespeitadas por usá-las. O meu saber etnográfico foi posto à prova, as sandálias não eram os motivos das risadas. Ainda que fosse mais fácil perguntá-las o motivo daquilo que eu reconhecia como 'deboche', resolvi adotar o caminho mais longo e conflitivo ao afirmar que a risada era por conta das sandálias. Ao direcionar-me a elas com perguntas defensivas, elas me responderam com um tom irônico: 'Nossa, professor! Seus pés são bonitos!' Ali eu acabei de descobrir que suas experiências me separavam dessas alunas.

A minha origem social me levava a crer que tinha os mesmos marcadores de classe dos/as estudantes. A partir do ocorrido percebi um conjunto de fatores que faziam nossas biografias distintas, ainda que compartilhasse a ideia de que éramos membros de camadas populares, eu era da cidade e a escola, localizava-se no campo. Eu vivia em um espaço com saneamento básico, o que não denunciava de imediato as condições de minha moradia. Os/as estudantes usavam sacos de arroz nos pés para proteger os sapatos da lama ou trocavam-os ao chegar na escola. Os meus pés e os pés dos alunos/das alunas denunciavam níveis diferenciados de camadas sociais, de estrutura e de espaço de vivência.

Ao problematizarmos o vivido, entendemos que para as alunas, o significado de suas risadas não passava diretamente pelo eixo econômico, ainda que ele objetivasse as condições expositivas de seus corpos. 0 fator que as levou ao riso foi explicitado na segunda frase dita por uma das alunas: 'Seu pé parece de mulher, professor'. Para elas, os meus pés projetavam uma imagem mais próxima ao universo delas do que ao dos alunos. A vaidade dessas alunas, fosse com o uso de esmalte ou por meio de outros acessórios, buscava formas de esconder as sequelas da falta de asfalto em seus bairros. De modo geral, esse episódio denunciava que as condições de moradias forjavam diferentes formas de masculinidades. Os meus pés não projetavam o referencial que elas majoritariamente conheciam sobre os pés de um homem.

Dialogando com Louro (1992), chegamos à conclusão que 


\section{periferio}

[...] sabemos todos que há um jeito entre nós de ser feminino e um jeito de ser masculino, há comportamentos, falas, gestos, posturas físicas, além de atividades e funções, que são socialmente entendidas como adequadas, "naturais", apropriadas, para as mulheres ou para os homens. Nossa referência a muitas dessas características é percebê-las quase como uma extensão da "natureza" de cada sexo (p. 58).

Nas experiências narradas, as identidades de gênero foram determinadas por polos opostos e desenhadas pelas expectativas relacionadas a cada sexo. Ainda nesse contexto, o meio-termo - entre um e outro gêneroobrigatoriamente ocupou o espaço da dúvida de gênero e/ou o espaço do desvio. Em nossa sociedade, a norma que estabeleceu-se culturalmente e é referendada pelos dispositivos históricos

[...] remete ao homem branco, heterossexual, de classe média urbana e cristão, este arranjo passou a ser a referência e não precisa mais ser nomeado. A nomeação deve ser um exercício para "outros" sujeitos, que se definirão e serão denominados a partir dessa referência. Assim, a mulher é representada como o "segundo sexo" e os gays e lésbicas são descritos como desviantes da norma heterossexual, podendo, como são nomeados, como o terceiro sexo (LOURO, 2001. p. 15-16).

O quadro descrito até aqui nos coloca frente a uma agenda políticopedagógica com contornos estruturantes na 'democracia sexual'. A construção dos corpos sexuados, historicamente naturalizados como diferentes, é mais um assunto da disputa de saberes que se instaurou na e com a escola. Assim, não somos nós sozinhos que determinamos o gênero de nossos corpos. Considerando que o gênero é constituído socioculturalmente e que seus significados são proliferados por meio de tecnologias educativas, é ele que acaba por significar o sexo. Assim, o gênero é configurado a partir de nossas leituras das tecnologias educativas e performativas que nos regulam. Talvez seja nessa encruzilhada que resida $(\mathrm{m})$ o(s) ponto(s) de fratura e de resistência aos movimentos de natureza da normalidade sexual. 


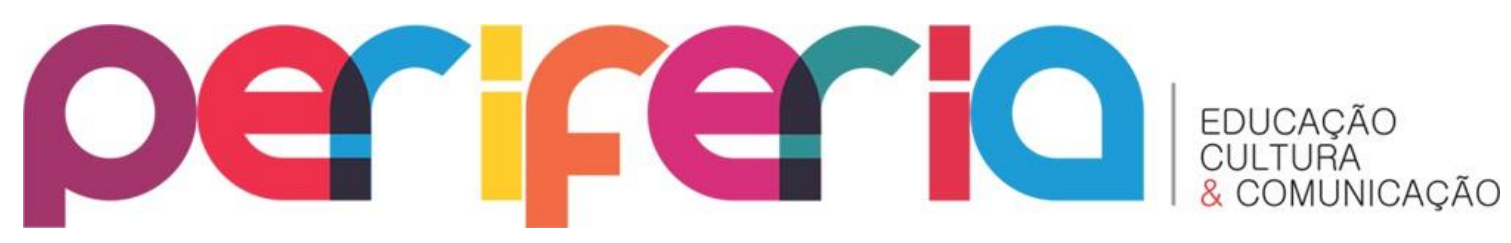

$\mathrm{Na}$ conjuntura atual, ainda que mantenhamos vários dos aspectos sexuais alicerçados na dicotomia, o conceito relacional e cotidiano de gênero ampliou-se para além dos polos opostos entre os sexos, sobretudo, a partir das críticas à ideia de Homem Universal elaboradas por diferentes movimentos sociais: feministas, negros/as e LGBTTTIQ (lésbicas, gays, bissexuais, travestis, transexuais, transgêneros, intersexuais, queer).

Pensamos que a visibilidade político-sexual proporcionada pelas identidades sexuais LGBTTTIQ, somada à projeção e à ocupação de mulheres em espaços de poder, originalmente voltados para homens, resultaram na pluralidade dessa(s) masculinidade(s) e feminilidade(s). A ação relacional entre as identidades de gênero foi flexibilizada e ampliada para além de pólos opostos de sexos: ela é realizada, inclusive, dentro das fronteiras do próprio ser/estar masculino e feminino.

Inspiração para o subtítulo desta seção, a afirmação de Marcela Lagarde - "nossas vidas são verdadeiras epistemologias"- baseia-se na ideia de que nossas existências, num mundo atravessado pela desigualdade, pela coerção social, pela competitividade e pelo terror das guerras, já estabeleceram a relevância teórico-metodológica e a veracidade vivida de nossos conhecimentos produzidos na condução da vida. Contudo, nós diríamos que nossas histórias/vidas são mais que esses estatutos: elas servem de inspirações para trazer às escolas as experiências vividas que produzem significados à vida e ao conhecimento.

Ainda que os discursos sobre os fazeres sexuais busquem governar dicotomicamente os corpos e estabelecer verdades sobre os sexos, a criatividade e o desejo proporcionados pela sexualidade borram os fazeres e redimensionam os gêneros que, por sua vez, impulsionam os movimentos curriculares e o repensar sobre os limites sociais, políticos, sexuais, econômicos de homens e de mulheres. Devemos entender que essa situação não é linear e nem tampouco desencadeada por simples jogos. Entretanto, o que aprendemos com os professores/as é que no interior da própria ordem, por dentro da própria lógica de regulação, existem resistências e acordos que 


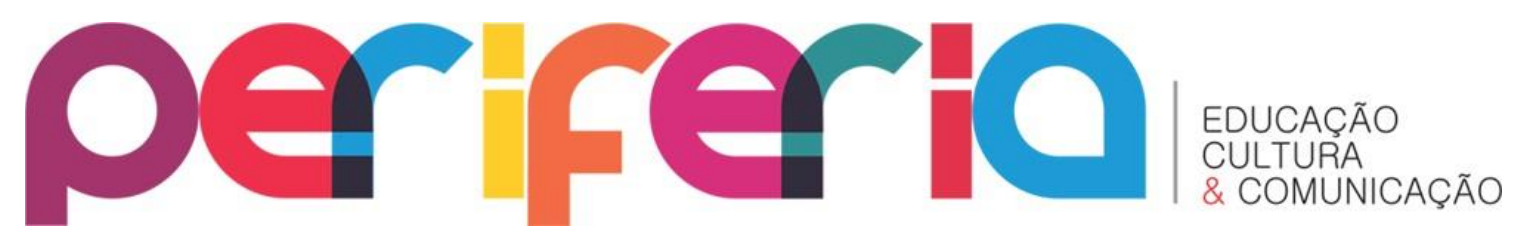

subvertem a lógica instituída e possibilitam novos/outros arranjos sociais e afetivos: isso movimenta e impulsiona a vida que, consequentemente, se encontra na escola.

As mulheres (lésbicas, bissexuais e heterossexuais) e a população LGBTTTIQ foram as primeiras a problematizar as diferenças de gênero. Esses coletivos de sujeitos têm sido os precursores em explorar a política da sexualidade ou a sexualidade como política. Ao apresentar os questionamentos aos juízos mais elementares sobre o sexo, o gênero e a sexualidade, incluídas as oposições heterossexual/homossexual, sexo biológico/gênero e homem/mulher, esses sujeitos desenvolveram novas formas de examinar o tema da identidade, refletindo-as nas políticas curriculares.

Assim como o ideal de Homem Universal foi o efeito de interesses políticos que, ao longo da história, buscaram estabelecer a categoria 'mulher' como o outro do 'homem'; a 'homossexualidade' vem sendo uma identidade retroalimentada pela lógica dicotômica heteronormativa e se caracterizando como o outro da 'heterossexualidade'. Pensamos que, como estratégia, poderíamos recorrer ao jogo difuso de poder, sugerido por Foucault (1988). Nessa tática política, a estratégia não seria transcender as relações de poder, mas multiplicar suas configurações até o ponto em que um modelo de regulação sexual deixe de ser hegemônico. É neste sentido que vemos a ampliação das letrinhas da sigla LGBTTTIQ: elas fazem parte dessa estratégia política de pulverizar a homossexualidade e destituir a lógica que retroalimenta a existência da heterossexualidade.

\section{CONSIDERAÇÕES FINAIS}

A vida constituiu-se em lócus privilegiado da experiência, do saber e do conhecimento produzidos neste artigo por meio da autoetnografia. A vida cotidiana ofereceu multiplicidades de momentos, de lugares, de espaços, de situações e de relações nas quais se originaram atos formativos de 


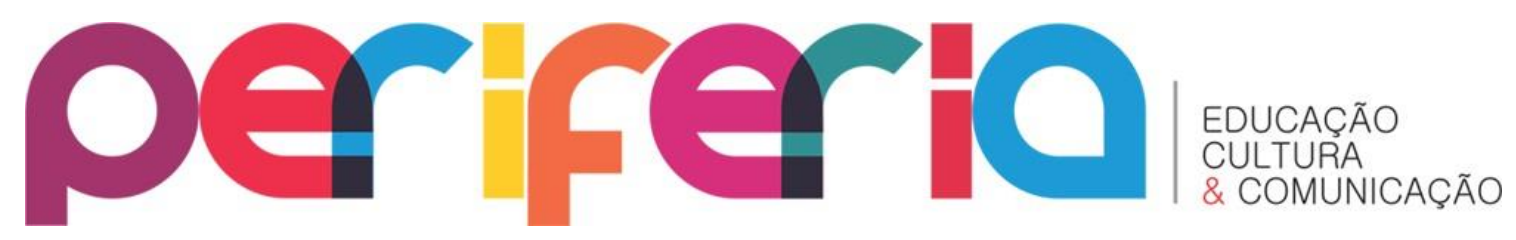

aprendizagens. Com elas, esperamos ter esclarecido que não encaramos a descrição autoetnográfica da vida sob a lente da racionalidade ocidental moderna, que vê o mundo como se tudo dependesse da ação consciente. Por essa razão, talvez, a prática docente não foi capaz de tomar outras decisões se não aquelas narradas no momento das experiências vividas e debatidas neste texto.

As narrativas autoetnográficas foram entendidas como leituras de experiências que arquitetaram, buscaram e reuniram elementos para compor a trama do que foi vivido. O tempo da vida foi, então, aquele passível de descrição. O tempo da experiência, ainda que datada, produziu sentidos e articulou intensamente a história de uma trajetória docente.

Ainda que as sexualidades e o gênero assumam configurações fluidas, instáveis, inacabadas e, sobretudo, locais, a ampla divulgação e a aceitação dessas categorias inscrevem-se em um contexto de crescente impacto da globalização socioeconômica: um mundo em que, cada vez mais, o que se sucede em uma cultura tem grande influência sobre as demais. Esse cenário nos descreve, por um lado, o quadro produtivo de identidades e nos sugere que as interações cotidianas têm o poder de criar e tornar as nomeações em 'senso comum'; por outro lado, o mesmo cenário nos revela um esforço quase ativista de vários sujeitos em contrariar as heterodesignações hegemônicas acerca das sexualidades e das performatividades de gênero marginais, a exemplo da experimentada pelo estudante Jonathan.

\section{REFERÊNCIAS}

BAKHTIN, M. Questões de literatura e estética: a teoria do romance. 5. ed. Trad. Aurora Fornoni Bernardini et al. São Paulo: HUCITEC, 2002.

BADINTER, E. XY: sobre a identidade masculina. Rio de Janeiro: Nova Fronteira, 1993.

BEAUVOIR, S. de. El segundo sexo. Madrid: Cátedra, 2005. 


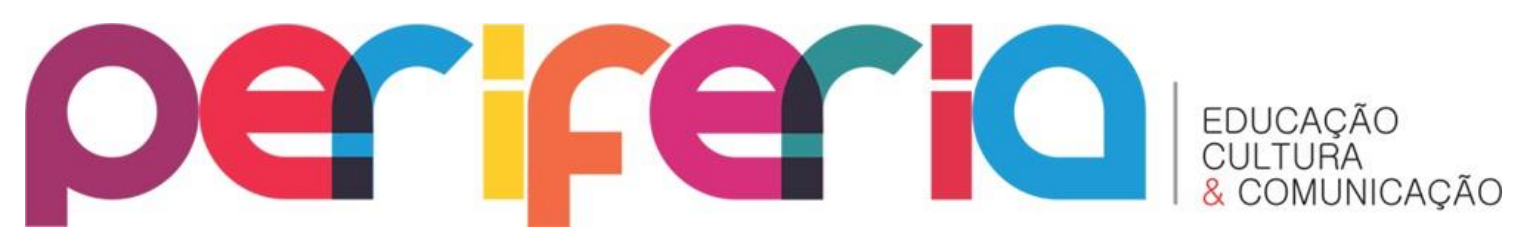

BONDÍA, J. L. Notas sobre a experiência e o saber de experiência. Trad. João Wanderley Geraldi. In: Revista Brasileira de Educação. Rio de Janeiro, n. 19, fev./mar./abr. 2002, p. 20-28. Disponível em:

<http://www.scielo.br/pdf/rbedu/n19/n19a02.pdf>. Acesso em 01 dez. 2010.

CAETANO, M. Performatividades reguladas: heteronormatividade, narrativas biográficas e educação. Curitiba: Appris, 2016.

; GOULART, T.; SILVA, M. Ensaio sobre a heteronormatividade: modos curriculares de aprendizagem das sexualidades e do gênero. In: Atos de Pesquisa em Educação. Blumenau/SC, vol. 11, n. 2, p. 634-655, ago./nov. 2016.

CONNELL, R. W. Políticas de masculinidade. Trad. Tomaz Tadeu da Silva. In: Educação e Realidade. Rio Grande do Sul, vol. 20, n. 2, p. 185-206, jul./dez. 1995.

. Masculinidades. Ciudad de México: UNAM-PUEG, 2003.

FREIRE, P. Pedagogia da autonomia: saberes necessários à prática educativa. Rio de Janeiro: Paz e Terra, 1996.

FOUCAULT, M. Vigiar e punir: nascimento da prisão. Petrópolis/RJ: Vozes, 1987. Graal, 1988.

História da sexualidade: a vontade de saber. Vol. 1. Rio de Janeiro:

. Microfísica do poder. Rio de Janeiro: Graal, 2002.

LOURO, G. L. Gênero, sexualidade e educação: uma perspectiva pósestruturalista. Petrópolis/RJ: Vozes, 1997.

. Heteronormatividade e homofobia. In: DINIZ, R. J. (Org.). Diversidade Sexual na Educação: problematizações sobre a homofobia nas escolas. Brasília-DF: Ministério da Educação, Secretaria de Educação Continuada, Alfabetização e Diversidade, UNESCO, 2009. p. 85-93.

. Pedagogias da sexualidade In. LOURO, G. L. (Org.). O corpo educado: pedagogias da sexualidade. Belo Horizonte: Autêntica, 2001. p. 9-34.

. Um corpo estranho: ensaios sobre a sexualidade e a teoria queer. Belo Horizonte: Autêntica, 2004.

- Uma leitura da história da educação sob a perspectiva do gênero. In: Teoria e Educação. Porto Alegre, n. 6, p. 53-67, 1992. 


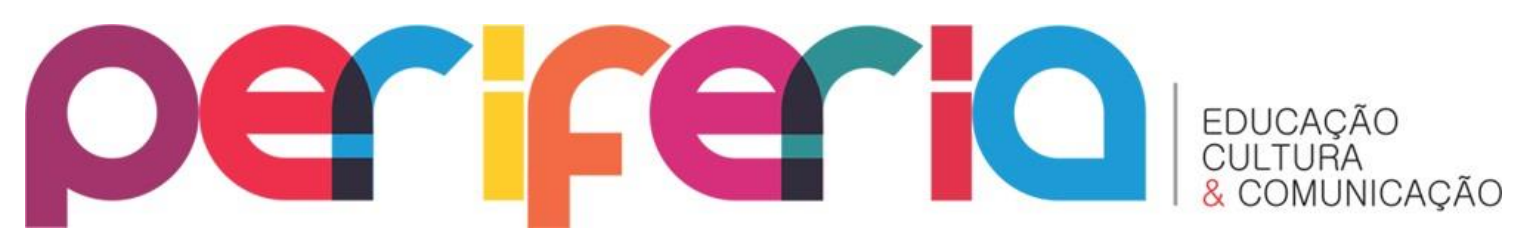

MEXICO. Ley General de Acceso de las Mujeres a una Vida Libre de Violencia. 2007. Disponível em

<http://www.gob.mx/cms/uploads/attachment/file/209278/Ley_General_de Acceso_de_las_Mujeres_a_una_Vida_Libre_de_Violencia.pdf $>$. Acesso em 20 jun. 2017.

MOTTA, P. M. R. da; BARROS, N. F. de. Autoetnografia. In: Caderno de Saúde Pública. Rio de Janeiro, vol. 31, n. 6, jun. 2015. Disponível em: <http://dx.doi.org/10.1590/0102-311XRE020615>. Acesso em 18 jun. 2017.

RANGEL, M. Representações e reflexões sobre o "bom professor".

Petrópolis/RJ: Vozes, 2001.

WITTIG, M. El pensamiento heterosexual y otros ensayos. Barcelona: Egales, 2006. 